\title{
Research reactor fuel element corrosion under repository relevant conditions: separation, identification, and quantification of secondary alteration phases of $\mathrm{UAl}_{x}-\mathrm{Al}^{\text {in }} \mathrm{MgCl}_{2}$-rich brine
}

\begin{abstract}
The corrosion of the $\mathrm{UAl}_{x}-\mathrm{Al}$ research reactor fuel type in synthetic $\mathrm{MgCl}_{2}$-rich brine (static batch-type experiments) was investigated with respect to the longterm safety of directly disposed research reactor fuel elements in salt formations. During corrosion, crystalline secondary phases were formed, which may serve as a barrier against radionuclide migration. For an optimized identification and quantification of the secondary phases using Xray diffraction, a sample treatment to separate and enrich the secondary phases is necessary. A grain size fractionation was carried out in iso-propanol. A chemical composition and phase characterization of the secondary phases was accomplished. The results of the chemical investigations reveal that only traces of $\mathrm{Al}$ and $\mathrm{U}$ were dissolved. The separation and enrichment of secondary phases were carried out reproducible and successfully. Due to the phase characterization by scanning electron microscopy/energy dispersive X-ray spectroscopy and X-ray diffraction the following secondary phases were unambiguously identified: $\mathrm{Mg}-\mathrm{Al}-\mathrm{Cl}$ layered double hydroxide, lesukite, Fe layered double hydroxide (green rust), lawrencite, Fe (elemental), and traces of uncorroded fuel $\left(\mathrm{UAl}_{4}\right)$. The quantitative analysis showed that LDH compounds and lesukite are the major crystalline phases. All other observed compounds were only present in trace amounts, i.e. constituting accessories. The Rietveld analysis also revealed the high content of amorphous phases of approximately $30 \%$, which are expected to include the uranium as $\mathrm{U}(\mathrm{OH})_{4}$.
\end{abstract}

Keywords: Research reactor fuel element, $\mathrm{UAl}_{x}-\mathrm{Al}$, Corrosion, Secondary phases, SEM-EDS, XRD.

\footnotetext{
*Corresponding Author: M. Klinkenberg, Institute of Energy and Climate Research (IEK-6) - Nuclear Waste Management and Reactor Safety, Research Centre Jülich GmbH, 52425 Jülich, E-mail: m.klinkenberg@fz-juelich.de

A. Neumann, H. Curtius, G. Kaiser, D. Bosbach: Institute of Energy and Climate Research (IEK-6) - Nuclear Waste Management and Reactor Safety, Research Centre Jülich GmbH, 52425 Jülich
}

\section{Introduction}

Research reactor fuel elements are composed for instance of metallic $\mathrm{UAl}_{x}-\mathrm{Al}$ or $\mathrm{U}_{3} \mathrm{Si}_{2}-\mathrm{Al}$, in contrast to $\mathrm{UO}_{2}$ fuel elements, which are used in commercial nuclear power plants. In Germany, the direct disposal of research reactor fuel elements in deep geological formations may be one disposal option [1]. This study is focused on a dispersed metallic $\mathrm{UAl}_{x}-\mathrm{Al}$ research reactor fuel type, which was used in the German research reactor FRJ-II (Research Centre Jülich).

Only a few studies are available, regarding the corrosion of $\mathrm{UAl}_{x}$-fuel under repository relevant conditions. Kaminski and Goldberg [2] investigated the corrosion of uranium-aluminide $\left(\mathrm{UAl}_{x}\right)$ fuels with modified ground water $\left(0.003\right.$ molar) at $90^{\circ} \mathrm{C}$ under oxidizing conditions. Kaminski and Goldberg observed a thin silica-substituted hydrous aluminum oxide gel layer on the surface of the fuel and an oxidation of the fuel, producing hydrated aluminum and uranyl oxohydroxide compounds (dehydrated shoepite and bequerelite phases). After $183 \mathrm{~d}, 7.9 \mu \mathrm{g}$ of uranium ( $<0.02 \%$ of total inventory) was released. A further study of Kaminiski et al. [3] focused on the colloid generation during the aqueous, oxic corrosion of $\mathrm{UAl}_{x}$-fuel and the determination of concentration, size distribution, and morphology of the colloids. These colloids carry $99 \%$ of the dissolved uranium fraction, whereas these studies are not comparable to our investigations due to the different experimental setups (drip tests and static batch) and conditions such as different $\mathrm{pH}$ values, oxidizing/anoxic conditions, and ionic strength.

Previous investigations at IEK-6 were performed with irradiated $\mathrm{UAl}_{x} \mathrm{Al}$-fuel samples, in order to contribute to the long-term safety analysis of directly disposed research reactor fuel elements. The corrosion behavior of this fueltype in a final repository relevant salt brine under nonoxidizing conditions and in the presence of iron-II ions was determined. Static batch-type corrosion experiments with an irradiated $\mathrm{UAl}_{x}$-Al fuel sample $(3.5 \mathrm{~g})$ were per- 
formed and it corroded completely in $400 \mathrm{~mL} \mathrm{MgCl}_{2}$-rich brine (15 molar) within 3.5 years $[4,5]$. In comparison, the corrosion of $\mathrm{UO}_{2}$ fuel in concentrated salt solutions is very slow and only $0.01 \%$ of the fuel corroded within 2 years under comparable conditions [6]. As a result of the fast corrosion process of the research reactor fuel element, radionuclides are released in a very short period of time compared to the geological time scale of some 100000 years. However, $\mathrm{Pu}, \mathrm{Am}, \mathrm{Eu}$, and U are re-immobilized [4, 5]. Different mechanisms may cause the immobilization of radionuclides like surface adsorption, ion exchange or structural incorporation into newly formed secondary phases. Secondary phases are of particular interest because they may act as a barrier with respect to radionuclide migration and ultimately define the source term in a safety case. Therefore, a reliable identification and quantification of secondary phases is the main objective.

First results were obtained by Mazeina et al. [7] who performed identical corrosion experiments with nonirradiated $\mathrm{UAl}_{x} \mathrm{Al}$-fuel samples. They could already show that after a complete corrosion of the non-irradiated $\mathrm{UAl}_{x} \mathrm{Al}_{\text {sample in }} \mathrm{MgCl}_{2}$-rich brine bischofite and $\mathrm{Mg}$-Al-Clhydrotalcite (layered double hydroxide, $\mathrm{LDH}$ ) form as crystalline secondary phases. The results of Mazeina et al. [7] were obtained by investigating the bulk untreated solid material after drying at $90^{\circ} \mathrm{C}$. Furthermore, after dialysis of the bulk sample in deionized water with subsequent drying at $90^{\circ} \mathrm{C}$, the $\mathrm{LDH}$ was found as main component. The LDH is of special interest due to its retardation capacity for radionuclides by anion exchange and structural incorporation/co-precipitation $[8,9]$.

The complete phase identification of secondary phases after corrosion of $\mathrm{UAl}_{x}$ - $\mathrm{Al}$ in $\mathrm{MgCl}_{2}$-rich brine is challenging, due to the partially very small particle size and the large variety of the phases present. Furthermore, the high amount of amorphous phases and the high water content complicates the analysis being performed by X-ray diffraction. An appropriate treatment of the secondary phases followed by an enrichment of single phases is necessary for a reliable identification and subsequent quantification of the secondary phases by X-ray diffraction. X-ray diffraction is used as a bulk analytical method, in order to identify and quantify the corrosion products using the Rietveld method. An identification of the secondary phases would in principle also be possible e.g. by TEM. However, a quantification of the bulk material is not possible due to the small amounts of samples, which are used for TEM analyses and hence are not representative.

In this present study, methods which have been successfully applied in soil science and clay mineralogy are used for the treatment of corrosion products of $\mathrm{UAl}_{x} \mathrm{Al}$ in
$\mathrm{MgCl}_{2}$-rich brine [10]. Based on different grain size, density of the phases, and the solubility in various solvents, a separation and enrichment of certain phases can be achieved. The focus of this study is to refine the separation, identification and subsequent quantification of the formed secondary phases.

\section{Experimental details}

\subsection{Corrosion test}

Static batch-type corrosion experiments of $\mathrm{UAl}_{x}$-Al-fuel samples were carried out in synthetic $\mathrm{CaCl}_{2}$ containing $\mathrm{MgCl}_{2}$-rich brine [4, 11]. This type of brine occurs in nature in potassium mines and was also found in exploration drillings at the Gorleben site, Germany [12]. Two identical experiments were carried out to evaluate the reproducibility of the sample treatment and analytical results. The chemical composition of the German reference brine (brine 2) is given in Table 1 [12] and the corrected $\mathrm{pH}$ value [13] was 5.7.

The corrosion experiments were carried out in glass autoclaves at $90^{\circ} \mathrm{C}$, under non-oxidizing conditions (Aratmosphere). For each experiment, $400 \mathrm{~mL} \mathrm{MgCl}_{2}$-rich brine, which was purged with Ar to remove dissolved gases like $\mathrm{CO}_{2}$ and $\mathrm{O}_{2}$, was added to one non-irradiated $\mathrm{UAl}_{x}$ Al-fuel element plate. The fuel element plates had dimensions of $20 \times 28 \times 1.5 \mathrm{~mm}$ and a mass of $c a$. $2 \mathrm{~g}$. The total U content of each fuel element plate was $0.12 \mathrm{~g} \pm 1 \%$ $\left({ }^{235} \mathrm{U}: 0.107 \mathrm{~g}, 90 \%\right.$ enrichment) and the Al content was $1.88 \mathrm{~g}$. Related to the geometric surface the $\mathrm{S} / \mathrm{V}$ ratio was $31.6 \mathrm{~cm}^{-1}$.

Under repository relevant conditions iron occurs in the system due to the corrosion of the container. To simulate the presence of iron-II, $10 \mathrm{~g} \mathrm{FeCl}_{2} \cdot 6 \mathrm{H}_{2} \mathrm{O}$ were dissolved in $400 \mathrm{~mL}$ brine [4].

Due to the corrosion of $\mathrm{Al}$, hydrogen was generated and determined by GC-measurements. A constant pressure value was interpreted as an indication of the end of the corrosion process. The corrosion process of the $\mathrm{UAl}_{x}$ Al fuel elements in $\mathrm{MgCl}_{2}$-rich salt brine was completed af-

Table 1: Chemical composition of the $\mathrm{MgCl}_{2}$-rich salt brine (brine 2). The uncertainty of the elemental concentrations is max. $\pm 1 \%$.

\begin{tabular}{lcccccc}
\hline $\begin{array}{l}\mathrm{Ca} \\
{[\mathrm{mol} / \mathrm{L}]}\end{array}$ & $\begin{array}{c}\mathrm{Cl} \\
{[\mathrm{mol} / \mathrm{L}]}\end{array}$ & $\begin{array}{c}\mathrm{K} \\
{[\mathrm{mol} / \mathrm{L}]}\end{array}$ & $\begin{array}{c}\mathrm{Mg} \\
{[\mathrm{mol} / \mathrm{L}]}\end{array}$ & $\begin{array}{c}\mathrm{Na} \\
{[\mathrm{mol} / \mathrm{L}]}\end{array}$ & $\begin{array}{c}\mathrm{SO}_{4} \\
{[\mathrm{~mol} / \mathrm{L}]}\end{array}$ & $\begin{array}{c}\mathrm{pH} \\
\mathrm{Corr}\end{array}$ \\
\hline 0.2690 & 9.8456 & 0.0190 & 4.6014 & 0.0706 & 0.0005 & 5.7 \\
\hline
\end{tabular}


ter a few months [4]. In total, approximately $400 \mathrm{~mL}$ suspension ( $\mathrm{pH}$ corr. 5.3 after corrosion) was obtained and $c a$. $20 \mathrm{~mL}$ of it were solid phases (wet sediment). In order to determine the chemical composition, an aliquot of the corrosion products was taken. The solid phase was divided into four parts. One part was used for the determination of the chemical composition, and the others for the identification and quantification of secondary phases.

\subsection{Chemical composition}

For the determination of the $\mathrm{Al}, \mathrm{Mg}$, and $\mathrm{Fe}$ content Inductively Coupled Plasma with Optical Emission Spectroscopy (ICP-OES) was used. The supernatant brine was filtered $(450 \mathrm{~nm})$ and a dilution of $1: 100(500 \mu \mathrm{L}$ filtrate, $49.5 \mathrm{~mL} 0.1 \mathrm{M} \mathrm{HNO}_{3}$ ) was performed. For the investigation of the solid phase, the dried solid $(2.55 \mathrm{~g})$ was dissolved in $200 \mathrm{~mL}$ concentrated $\mathrm{HNO}_{3}$, filtered $(450 \mathrm{~nm})$ and a $1: 100$ dilution was prepared. The measurements were done with a TJA-IRIS instrument.

To determine the $\mathrm{U}$ content a Liquid Scintillation Counter (LSC) TRI-CARB 2020 (PerkinElmer) and $\alpha$ spectrometry ( $\alpha$-analyzer, Canberra-Packard $\mathrm{GmbH}$ ) were used. The total activity was measured by LSC. Therefore, $500 \mu \mathrm{L}$ of the filtered solution and dissolved solid, respectively, were diluted in $1.5 \mathrm{~mL}$ water and $8 \mathrm{~mL}$ Hionic Fluor Cocktail (Canberra/Perkin Elmer). The instrument was calibrated using external standards and the detection limit was $0.1 \mathrm{~Bq}$ per sample. The associated uncertainty for these measurement conditions was $\pm 0.5 \mathrm{wt} .-\%$. The activity ratio of the uranium isotopes ${ }^{234} \mathrm{U}$ and ${ }^{235} \mathrm{U}$ was determined by alpha-spectroscopy measurements, and resulted in $96 \%{ }^{234} \mathrm{U}$ to $4 \%{ }^{235} \mathrm{U}$.

\subsection{Sample preparation and enrichment of secondary phases for phase analysis (XRD)}

For the identification and quantification of the secondary phases using XRD, a separation of the corrosion products is required. The starting product is a suspension, consisting of crystalline and amorphous phases with different grain sizes $(<1 \mathrm{~mm})$ in high molar brine. One problem occurs upon the drying of the bulk samples and the precipitation of bischofite $\left(\mathrm{MgCl}_{2} \cdot 6 \mathrm{H}_{2} \mathrm{O}\right)$ from the brine. The main difficulty is its hygroscopic behavior. The water and the bischofite interfere with the XRD-measurements, because they cause an elevated background and overlapping peaks. Hence, it is necessary to remove the bischof- ite, but without dissolution or alteration of the secondary phases of interest. Therefore, the samples were treated with different solvents: water, iso-propanol, and acetone. For the selection of the solvents, solubility tests were done. Therefore, acetone, ethanol, iso-propanol, ethyl acetate, tributylphosphate, and water were tested with the compounds $\mathrm{MgCl}_{2}, \mathrm{AlCl}_{2}$, and LDH. From these solvents, water, iso-propanol, and acetone were chosen for the sample treatment. Water was chosen due to the comparability of the results with the previously performed study by Mazeina et al. [7]. Iso-propanol was chosen because of the lower solubility compared to water and the good solubility of bischofite, which is the most interfering phase, whereas other salts are still present and are not dissolved. During the treatment with water it is most likely that not only the bischofite, but also newly formed secondary phases may be dissolved. The solubility of secondary phases for iso-propanol is lower and for acetone the lowest. For example the solubility for $\mathrm{NaCl}$ in these solvents at $25^{\circ} \mathrm{C}$ is: $360 \mathrm{~g} / \mathrm{kg}$ (water), $0.03 \mathrm{~g} / \mathrm{kg}$ (iso-propanol), and $0.00042 \mathrm{~g} / \mathrm{kg}$ (acetone) [14].

For the enrichment of secondary phases the following procedure was applied (depicted in the flow chart Figure 1).

After taking off the supernatant aqueous solution for the chemical analysis $(200 \mathrm{~mL})$, the remaining suspension was homogenized by shaking and divided into four parts. Attention should be paid to a homogeneous distribution of fine and coarse particles to avoid an enrichment of single phases, which cannot be excluded completely. For the enrichment of the solid, the samples were centrifuged and the supernatant brine was removed. Afterwards, a washing step followed by using $50 \mathrm{~mL}$ acetone, iso-propanol and water, respectively. The samples treated with acetone and iso-propanol were washed three times and the water treated sample was dialyzed.

For the enrichment, properties like different grain sizes and density of the single phases were used. Initially, all particles $>63 \mu \mathrm{m}$ of the iso-propanol and water treated sample were separated by wet sieving. The separation of finer grain sizes was carried out by sedimentation using Atterberg-cylinders. According to the Stokes's Law, spherical particles in a fluid are settling with different velocities, depending on their size (sphere equivalent diameter), density and the viscosity of the fluid.

The sample was homogenized with a fluid (isopropanol or water) in the Atterberg-cylinder and dispersed by shaking. After an appropriate settling time, the suspension above the ground was removed, collected and dried. This procedure was repeated until the supernatant fluid was clear. Particles $<2 \mu \mathrm{m}$ were separated. The remaining 


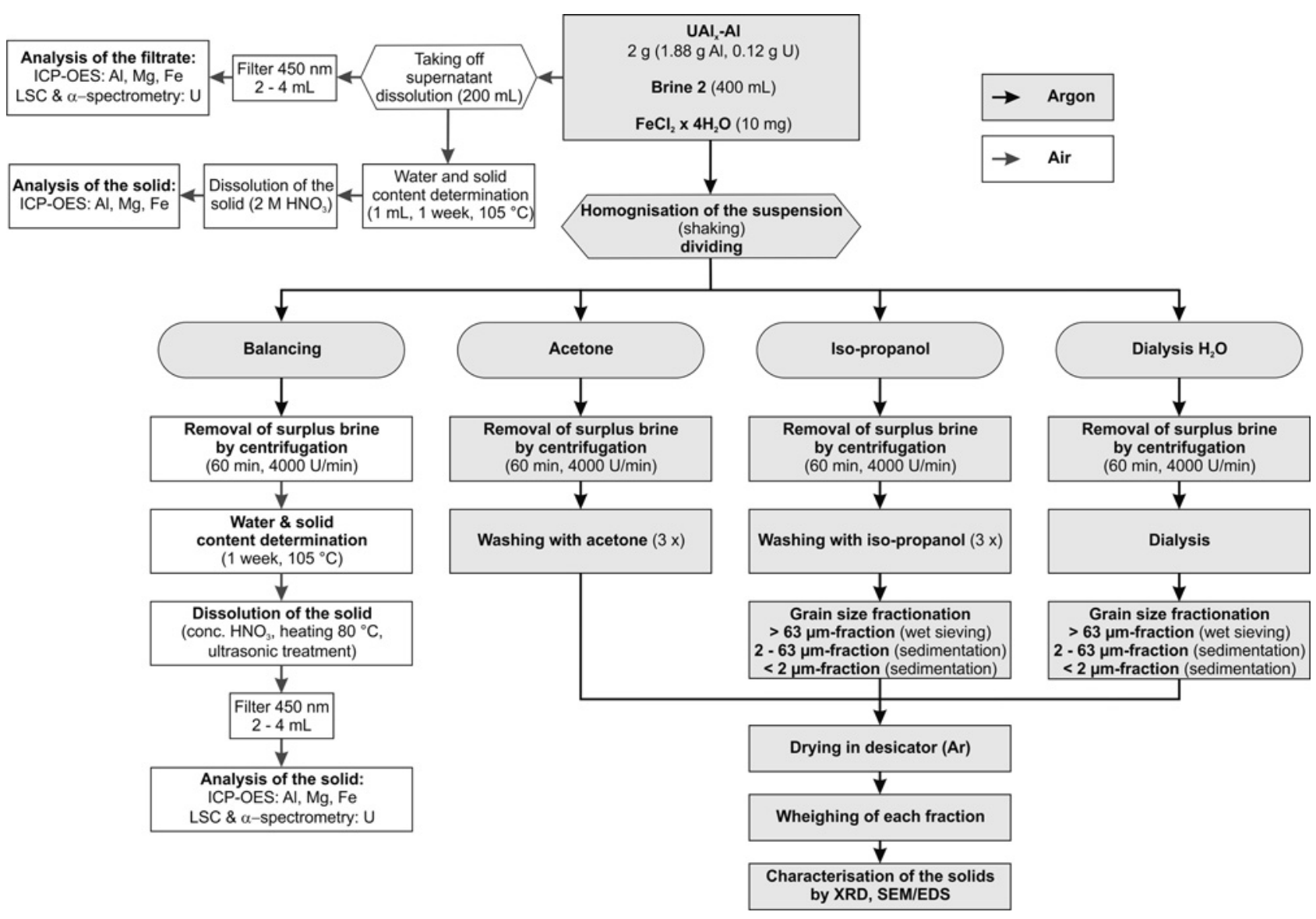

Fig.1: Flow chart of the sample treatment procedure.

fraction in the Atterberg-cylinder was between $2 \mu \mathrm{m}$ and $63 \mu \mathrm{m}$. The Stokes grain size of the obtained fractions were dried in a desiccator under Ar-atmosphere. The mass of the differently treated fractions of the samples was determined and subsequently analyzed by SEM/EDS and XRD.

\subsection{Electron microscopically characterization}

The scanning electron microscopy (SEM) investigation was performed by using the environmental scanning electron microscope FEI Quanta $200 \mathrm{~F}$. The measurements were carried out in a low-vacuum mode at $0.6 \mathrm{mbar}(20 \mathrm{kV}$, spot size 4, working distance $10 \mathrm{~mm}$ ). When using this mode, sputtering of the samples with gold or carbon is not necessary and artifacts are avoided. The samples were prepared as powders/grains on adhesive carbon tabs. The microscope is equipped with the EDS-system Genesis (EDAX).

\subsection{Phase identification and quantification of secondary phases by XRD and Rietveld}

For the qualitative phase identification, XRDmeasurements were performed. The powder diffractometer D8 ADVANCE, Bruker-AXS GmbH $(\theta-\theta$-geometry, radius $250 \mathrm{~mm}$ ) was used. For the XRD measurements, $\mathrm{Cu} K_{\alpha}$ radiation $\left(\lambda_{1}=1.54059 \AA\right)$ was applied and a NaI scintillation point detector or a VÅntec line detector was used. The instrument was equipped with a climate chamber MRI Hot Humidity (Bruker-AXS). The measurements were carried out under $\mathrm{N}_{2}$-atmosphere at room temperature, in order to exclude $\mathrm{CO}_{2}, \mathrm{O}_{2}$ and $\mathrm{H}_{2} \mathrm{O}$ from the samples. The data mining for the phase identification was evaluated with the DiffracPlus Eva software by retrieving the powder diffraction file (PDF-2) database of the International Centre of Diffraction Data ICDD.

In order to assess the amount of each crystalline phase and the amorphous content by the Rietveld method [15, 16], samples were intimately mixed with an internal non- 
certified zincite (Merck) standard of known weight. This standard was also used as reference, in order to correct manually the small deviations of the measured diffractograms. These are due to displacement errors resulting from the sample preparation.

For the XRD measurements, $\mathrm{Cu} K_{\alpha}$ radiation at $40 \mathrm{kV}$ and $40 \mathrm{~mA}$ was applied. To account for the iron fluorescence or any other parasitic radiation like $\mathrm{Cu} K_{\beta}$ a graphite monochromator was used for their suppression. The automatic aperture system was adjusted to $12 \mathrm{~mm}$ for the X-ray radiation exposition of the sample. Primary soller slits with a device angle of $2.376^{\circ}$ were applied to suppress axial divergence of the beam. The XRD measurements have been carried out in continuous mode with a step size of $0.02^{\circ}$ and with 10 seconds per step.

The structural analysis and the secondary phase quantification have been carried out with the software packages TOPAS [17] and BGMN [18]. Both programs are based on the fundamental parameter approach, which considers the diffractometer geometry, i.e. physical parameters in order to describe the device function.

\section{Results and discussion}

\subsection{Chemical composition}

After corrosion, the corrected $\mathrm{pH}$ value of the solution under Ar-atmosphere was 5.3. The content of $\mathrm{Al}, \mathrm{Fe}$, and $\mathrm{U}$ of the liquid fraction of the samples were determined. The results of the Al determination showed that only a minor amount of $\mathrm{Al}$ was released into the aqueous solution $(1-2$ wt. $-\% \pm 0.5$ wt.- $\%)$. Hence, most of the $\mathrm{Al}$ was in solid state. About half of the iron (53-56 wt. $\% \pm 5 \mathrm{wt} \%$ ) was still present in the liquid phase. Only a minor amount of $\mathrm{U}$ was dissolved in the aqueous solution ( $3 \mathrm{wt} .-\% \pm 0.5 \mathrm{wt}$. $\%)$. Thus, $\mathrm{Al}$ and $\mathrm{U}$ were in the solid phase. The chemical analyses of the solid phase confirm these results. In addition, these observations confirmed the results of the hot cell experiments with irradiated fuel, where $U$ was also not detected in the aqueous solution [5].

\subsection{Sample preparation and enrichment of secondary phases}

In order to examine the efficiency of the sample-treatment, the mass and percentage of the separated grain size fractions were determined after the treatment with isopropanol, water, and acetone (Table 2).
Table 2: Mass and proportion of the separated grain size fractions.

\begin{tabular}{llcc}
\hline & Fraction & [g] & [wt. \%] \\
\hline Acetone bulk & & 3.27 & \\
\hline Iso-propanol & $>63 \mu \mathrm{m}$ & 0.94 & 55 \\
& $2-63 \mu \mathrm{m}$ & 0.24 & 14 \\
& $<2 \mu \mathrm{m}$ & 0.53 & 31 \\
\hline Wuter & Sum & 1.71 & 100 \\
\hline & $>63 \mu \mathrm{m}$ & 0.39 & 43 \\
& $2-63 \mu \mathrm{m}$ & 0.32 & 36 \\
& $<2 \mu \mathrm{m}$ & 0.19 & 21 \\
\hline Solid for chemical analysis & Sum & 0.90 & 100 \\
\hline & & 2.55 & \\
\hline
\end{tabular}

In total, eight sub-samples were obtained for each experiment, including the sample for the chemical analysis. The fractions $<2 \mu \mathrm{m}, 2-63 \mu \mathrm{m}$, and $>63 \mu \mathrm{m}$ were obtained for the samples, which were treated with isopropanol and water. Due to the low viscosity of acetone, the separation via sedimentation was not possible; therefore, only a bulk sample was obtained for the acetone treated samples. Furthermore, the total solid content of all fractions was calculated. The highest mass of $3.27 \mathrm{~g}$ was determined for the sample, which was treated with acetone, because bischofite was still present. Specimens treated with iso-propanol showed a significantly lower mass (sum $1.7 \mathrm{~g}$ ), because bischofite was dissolved. The lowest amounts of material were obtained for water treated samples (sum $0.90 \mathrm{~g}$ ) due to the dissolution of further phases. The results confirm the expected effects of the different solubility of secondary phases in acetone, isopropanol, and water on the samples. The grain size distribution showed that particles $>63 \mu \mathrm{m}$ (55 wt \%) represent the main fraction of the isopropanol treated sample as well as of the water treated sample. For both experiments similar amounts for the different fractions were obtained, which indicated a good reproducibility of the corrosion experiments and the sample treatment.

\subsection{Electron microscopically characterization}

The seven subsamples (one acetone treated sample, three grain size fractions of the iso-propanol treated sample, and 3 grain size fractions of the water treated material) were characterized by SEM/EDS.

The treatment with acetone was in terms of enrichment and separation of singles phases not successful, due to the insufficient dissolution of bischofite. Hence, these 

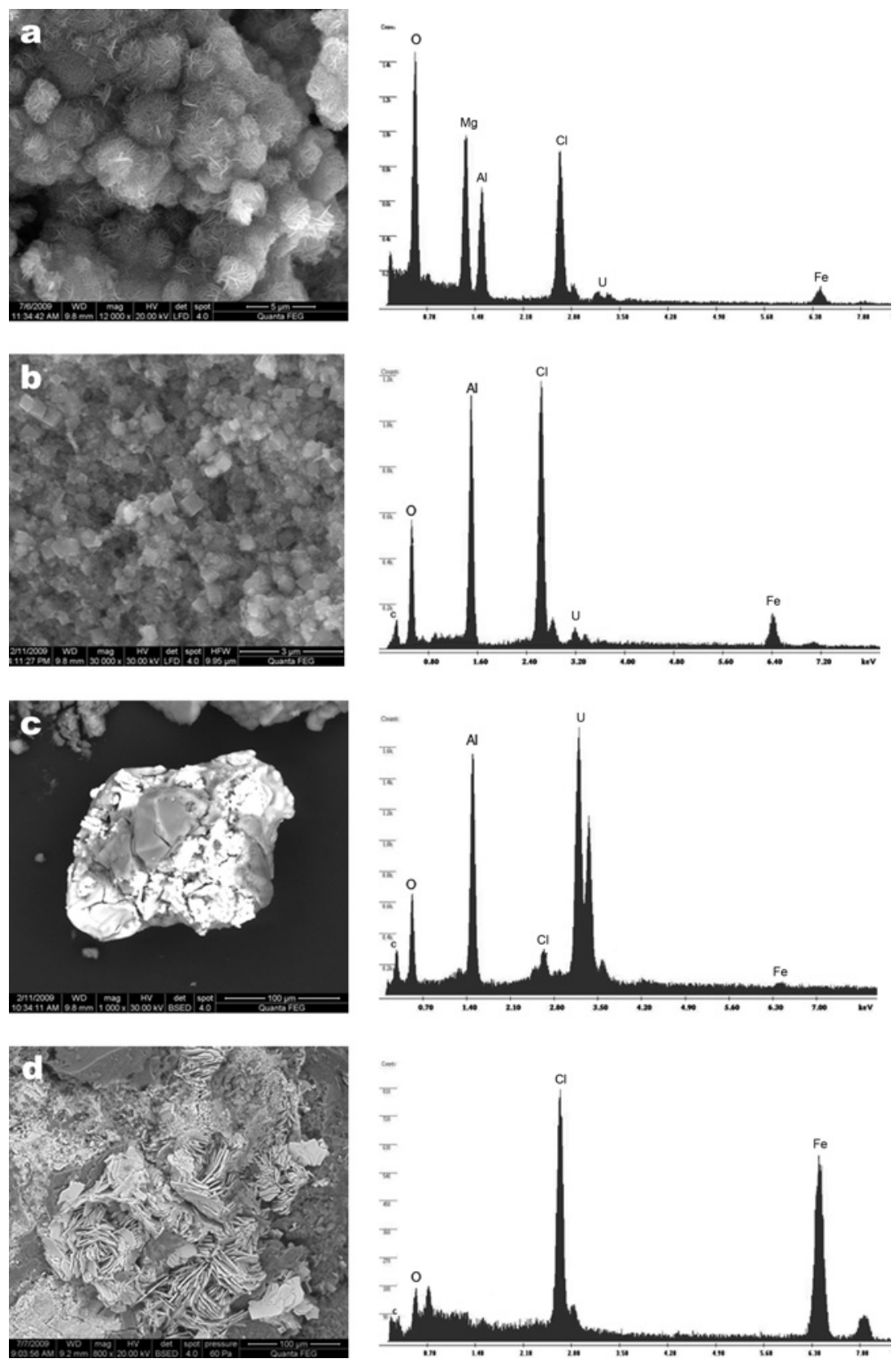

Fig. 2: Fraction $>63 \mu \mathrm{m}$, iso-propanol a) LDH-crystals forming a sand rose structure (SE); b) cubic crystals of lesukite (SE); c) aggregate of uranium (bright areas) and aluminum (BSE); d) platy crystals of a $\mathrm{Fe}, \mathrm{Cl}$ phase (lawrencite) (BSE).

samples were not taken into account for further investigations by SEM/EDS.

The largest grains of the $>63 \mu \mathrm{m}$ fraction of the isopropanol treated samples were above $500 \mu \mathrm{m}$. The separated coarse grains mainly consisted of aggregates. Secondary phases were grown onto the surfaces of these coarse grains. Platy crystals were visible in Figure 2a, which were forming aggregates of sand rose structure. The EDS-analysis identified $\mathrm{Mg}, \mathrm{Al}, \mathrm{Cl}$, and $\mathrm{O}$ as major components. The morphology and chemical composition were typical for LDHs. Minor amounts of Fe and U were also detected. A further secondary phase consisted of $\mathrm{Al}, \mathrm{Cl}$ and $\mathrm{O}$ and formed cubic crystals (Figure $2 b$ ). This phase may be lesukite. $\mathrm{U}$ seemed to be associated with $\mathrm{Al}$ in coarse aggregates. Bright areas in Figure 2c represent $U$ and grey areas Al. Besides, the EDS-spectrum depicts O, which indicates an oxidation of the $\mathrm{Al}$ and U. Furthermore, Fe-compounds exist, e.g. platy crystals (lawrencite), consisting of $\mathrm{Fe}, \mathrm{Cl}$, and small amounts of $\mathrm{O}$ (Figure 2d). 

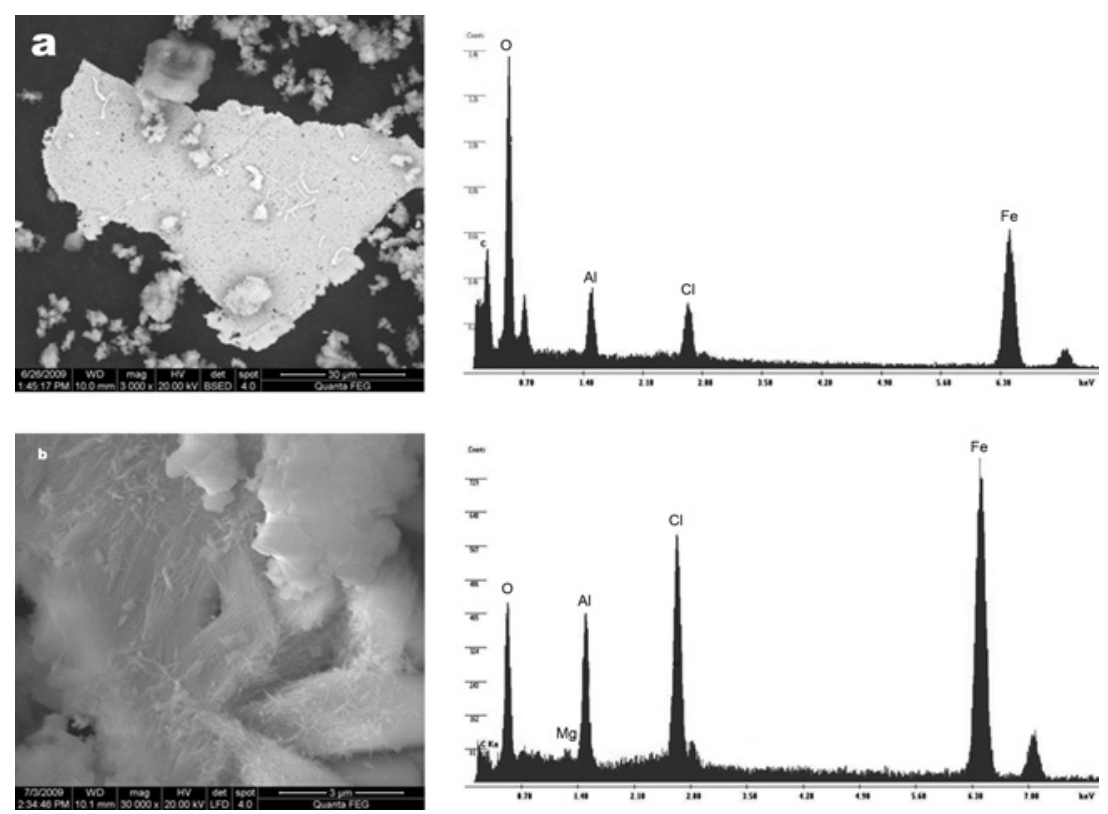

Fig. 3: Fraction 2-62 $\mu \mathrm{m}$, iso-propanol a) Fe-phase crust (BSE); b) fibrous crystals (SE).

In the $2-63 \mu \mathrm{m}$ fraction of the iso-propanol treated sample Fe-phases, forming coarser crusts, were common. This development of crusts was attributed to sample drying, because of their sizes larger than $63 \mu \mathrm{m}$ (Figure 3a). Furthermore, fibrous crystals were visible (Figure $3 b)$. Similar to the previously described $>63 \mu \mathrm{m}$ fraction, $\mathrm{LDH}$, lesukite, and uranium associated with aluminum occurred in this fraction.

The main constituents of the $<2 \mu \mathrm{m}$ fraction of the iso-propanol treated sample were cubic crystals of lesukite, consisting of $\mathrm{Al}, \mathrm{Cl}$, and $\mathrm{O}$. The edge length of these crystals was measured and the results are depicted in Figure 4a. The mean crystal size was approximately $240 \mathrm{~nm}$. LDHs with typical sand rose structure were only present in minor amounts (Figure 4b). Furthermore, Fe- phases were included, forming single crystals or crustaceous aggregates.

In conclusion, for the iso-propanol treated samples the following phases could be identified: LDH, lesukite, Fe-phases (lawrencite), and U associated with Al in coarser aggregates. An enrichment of iron-phases could be observed in the $2-63 \mu \mathrm{m}$ fraction. The lesukite was enriched in the $<2 \mu \mathrm{m}$ fraction.

For the water treated sample, coarse aggregates of aluminum oxides/-hydroxides were identified as main constituents of the $>63 \mu \mathrm{m}-$ fraction (Figure 5). Moreover, Fe-oxides/-hydroxides were included, forming single crystals or crustaceous aggregates. Uranium occurred associated with aluminum in coarse aggregates $(20-50 \mu \mathrm{m})$. This fraction contained low amounts of $\mathrm{Mg}$ and $\mathrm{Cl}$. Accordingly, there was only a minor content of LDHs.
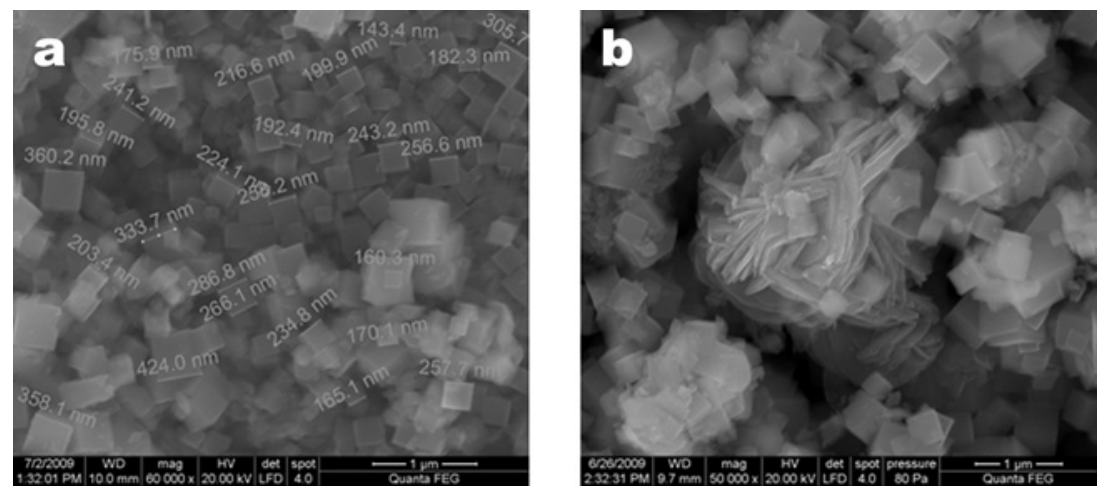

Fig. 4: Fraction $<2 \mu \mathrm{m}$, iso-propanol a) cubic crystals of lesukite (SE); b) LDH sand rose surrounded by lesukite (SE). 

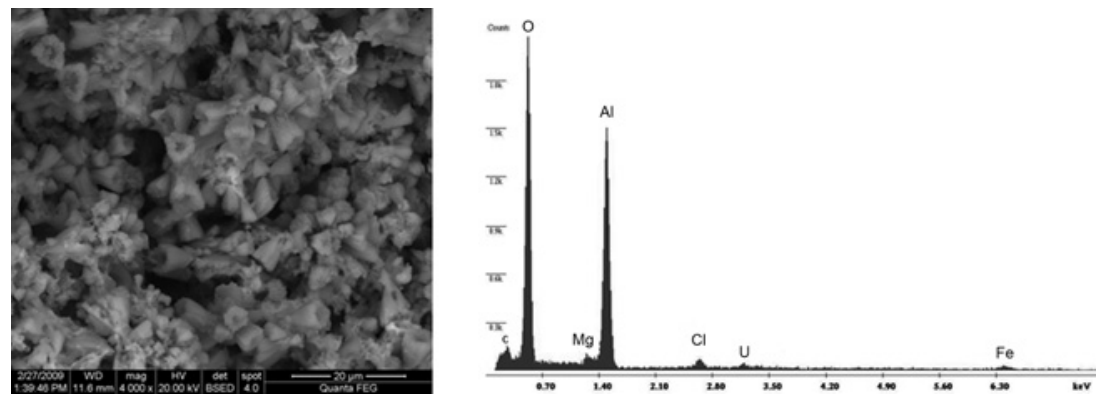

Fig. 5: Fraction $>63 \mu \mathrm{m}$, iso-propanol: Aggregate of aluminum oxide/-hydroxide (BSE) and associated EDX-spectrum.

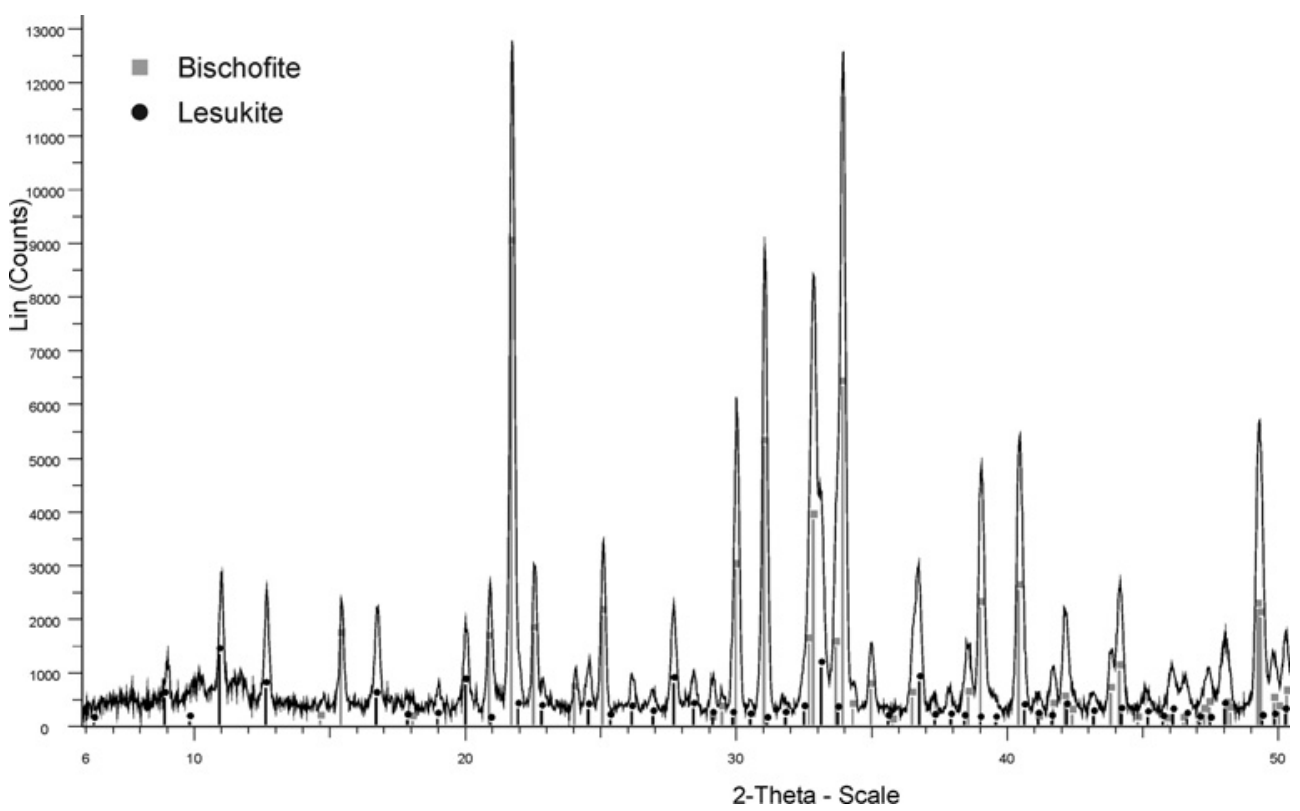

Fig. 6: Diffractogram of the acetone treated sample and the main components bischofite and lesukite.

The main constituents of the $2-63 \mu \mathrm{m}$ fraction of the water treated sample were aluminum oxides/-hydroxides. Also, Fe-phases (aggregates, crusts, crystals) and uranium/aluminum occurred. The $<2 \mu \mathrm{m}$ fraction was dominated by aluminum oxides/-hydroxides, as it was observed for the previously investigated water treated fractions.

In conclusion, for the water treated samples an enrichment of Al-oxides/hydroxides, particularly in the $<2 \mu \mathrm{m}$ fraction, could be observed. Only traces of LDH could be found. The lesukite was completely dissolved by the water. Furthermore, small amounts of Fe-phases and U associated with $\mathrm{Al}$ occured.

\subsection{Phase identification}

The observations done by SEM were verified by qualitative XRD measurements. Figure 6 shows the diffractogram of the acetone treated sample.
Strong peaks of bischofite are visible, which confirms the insufficient dissolution of bischofite by acetone. The XRD pattern of the acetone treated sample is similar to a diffractogram of an untreated sample. Due to the hygroscopic behavior of the bischofite and the resulting water content, it shows an elevated background, which was corrected. Moreover, overlapping peaks complicate a reliable identification of further secondary phases. Bischofite and lesukite were the only phases, which could be identified in this sample.

The diffractograms of the $\langle 2 \mu \mathrm{m}, 2-63 \mu \mathrm{m}$, and $>$ $63 \mu \mathrm{m}$ fraction of the iso-propanol treated sample clearly showed that bischofite was dissolved completely and other crystalline phases could be detected (Figure 7).

For the $<2 \mu \mathrm{m}$ fraction of the iso-propanol treated sample lesukite was determined as main component. Traces of LDH and akaganeite also occurred. In the 2-63 $\mu \mathrm{m}$ fraction MgAl-LDH, Fe-LDH (green rust), lawrencite, and lesukite were present. The $>63 \mu \mathrm{m}$ 


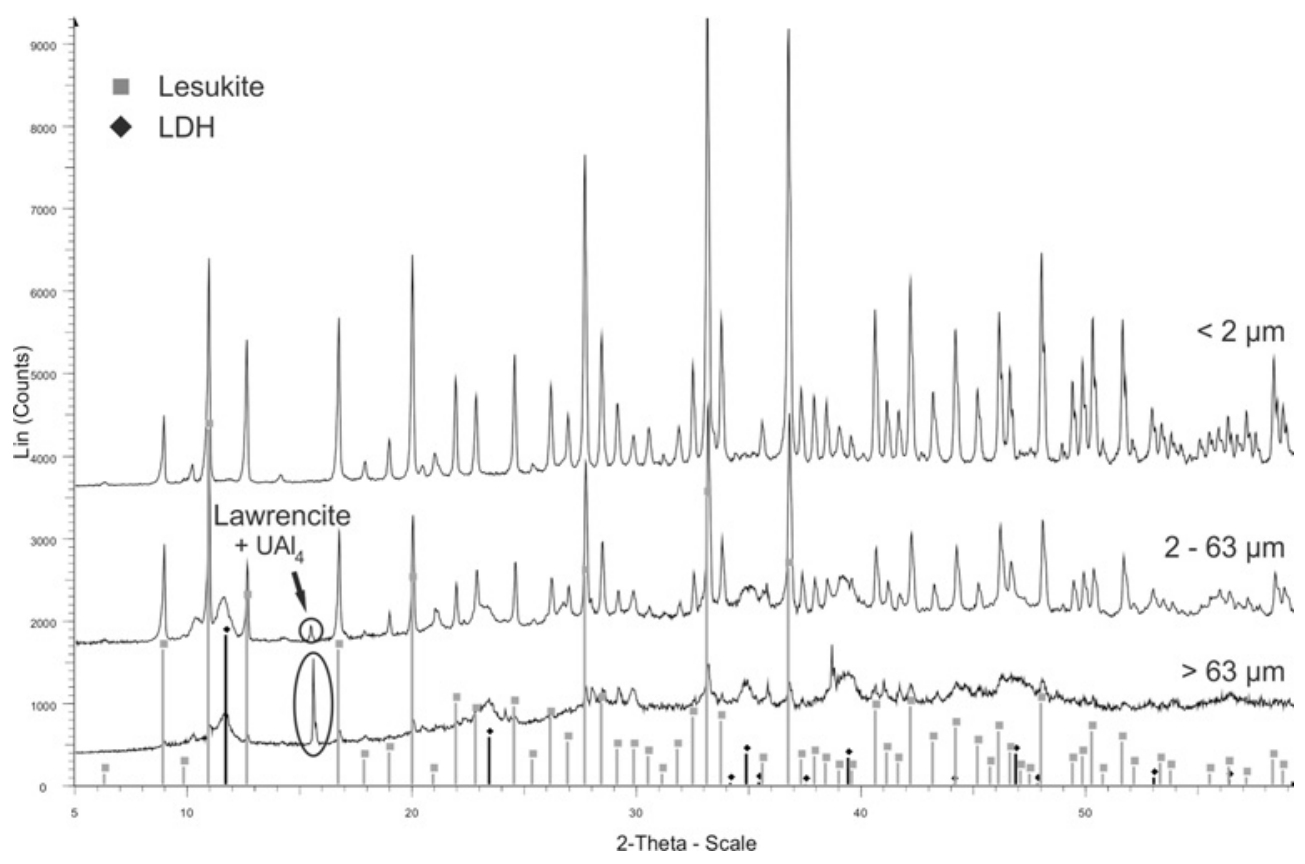

Fig. 7: Diffractograms of the $<2 \mu \mathrm{m}$ (top), $2-63 \mu \mathrm{m}$ (middle), and $>63 \mu \mathrm{m}$ (bottom) fraction of the iso-propanol treated sample and the main components lesukite and LDH.

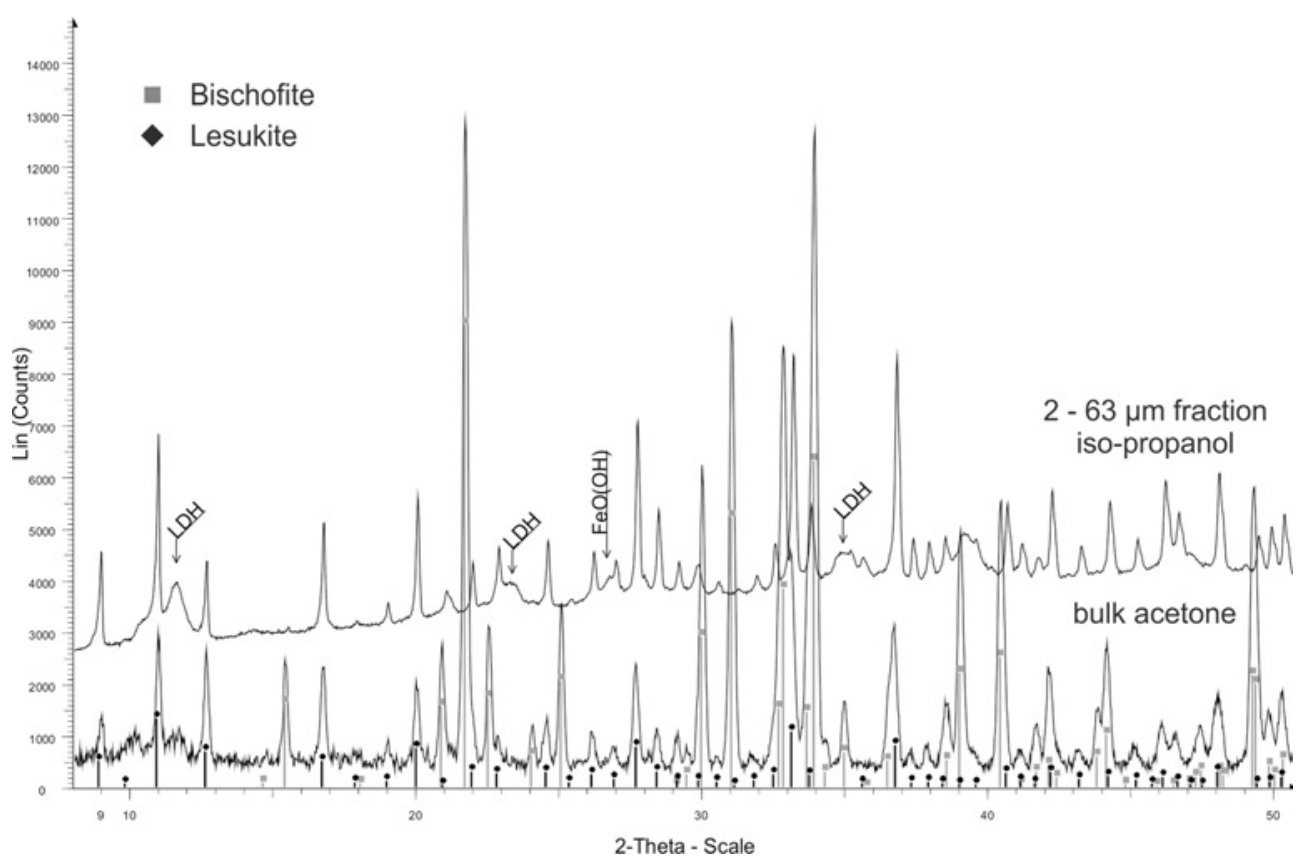

Fig. 8: Diffractograms of the bulk acetone treated sample (bottom) and the 2-63 $\mu \mathrm{m}$ fraction of the iso-propanol treated sample (top) and the main components bischofite and lesukite.

fraction additionally contained elemental iron, traces of uncorroded fuel $\left(\mathrm{UAl}_{4}\right)$, goethite, and lepidocrocite. Akaganeite could not be detected in this fraction. The sample treatment with iso-propanol and subsequent grain size fractionation clearly led to an enrichment of lesukite in the $<2 \mu \mathrm{m}$ fraction and to an enrichment of LDH in the $2-63 \mu \mathrm{m}$ fraction.

A comparison of the diffractograms of the bulk acetone treated sample and the $2-63 \mu \mathrm{m}$ fraction of the isopropanol treated sample (Figure 8) emphasizes the effect 


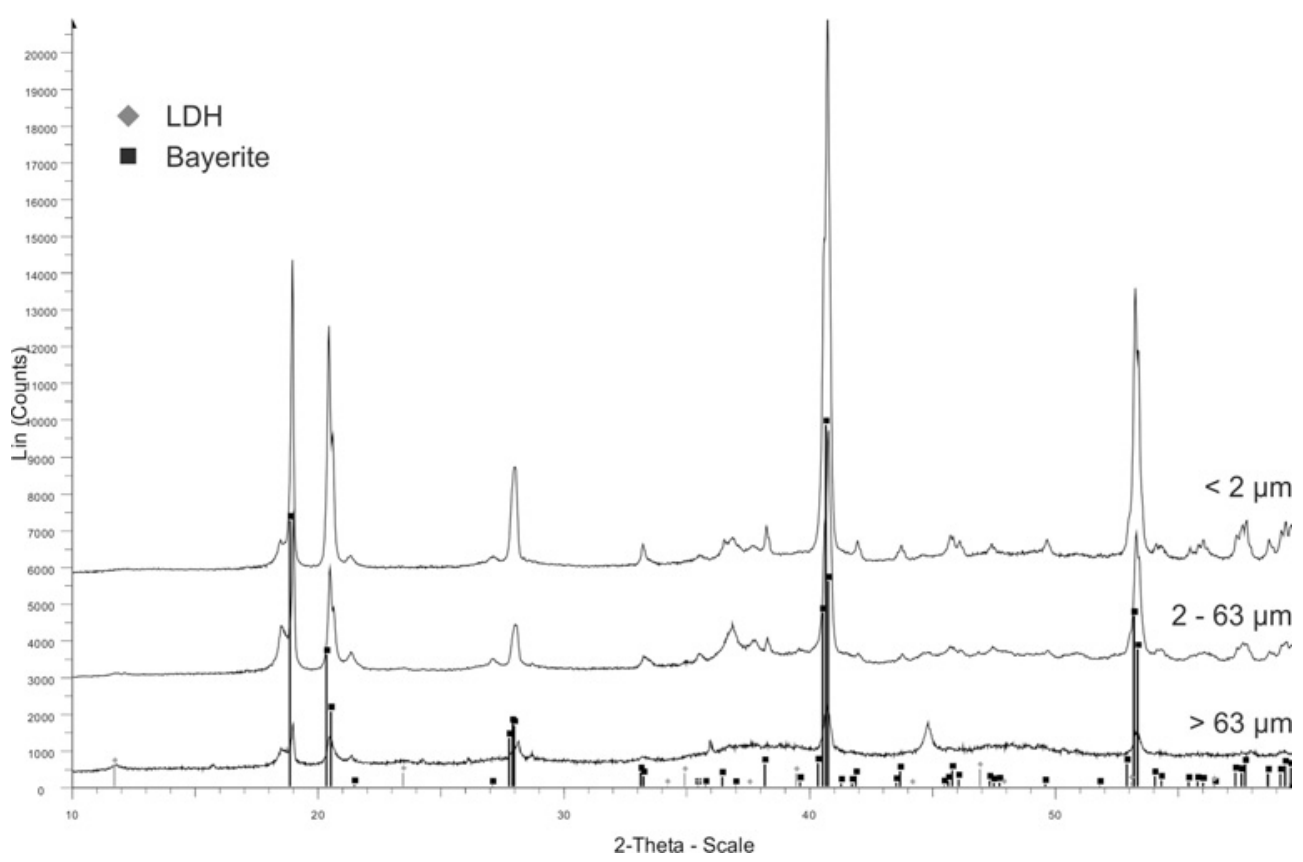

Fig. 9: Diffractograms of the $<2 \mu \mathrm{m}, 2-63 \mu \mathrm{m}$, and $>63 \mu \mathrm{m}$ fraction of the water treated sample and the main components bayerite and LDH.

of the sample treatment and its necessity for a reliable phase identification.

The diffractogram of the iso-propanol treated sample is less noisy than the XRD-pattern of the acetone treated sample. Furthermore, the absence of the bischofite peaks is clearly visible and confirms its complete dissolution. Due to the disappearance of the bischofite peaks, phases like LDH and akaganeite, for example, can be assigned, which are not visible in the lower diffractogram.

For the water treated samples (Figure 9), only the Alhydroxides bayerite, nordstrandite, and gibbsite were determined in the $<2 \mu \mathrm{m}$ fraction.

These phases also represent the main components of the two coarser fractions. The $2-63 \mu \mathrm{m}$ fraction additionally contained MgAl-LDH. Traces of $\mathrm{UAl}_{x}$ alloy and elemental Fe were also found in the $>63 \mu \mathrm{m}$ fraction. The appearance of Al-hydroxides can be explained by the dissolution of lesukite.

The results of the qualitative XRD analysis for the isopropanol and water treated samples are summarized in Table 3.

In conclusion, the main difference between the differently treated samples was the stability of the aluminum containing compounds. The lesukite was not stable in water and was dissolved completely, instead Al-hydroxides precipitated. Accordingly, it can be concluded that the water treatment did not provide representative results for the secondary phase inventory of the investigated system. Only the iso-propanol treatment reveals reliable results.
Compared to the measurements of Mazeina et al. [7], significant improvements in terms of the secondary phase identification could be achieved by the enrichment and separation procedure applied in this study. The formation of Al-Mg-Cl-LDH could be confirmed in this present study. In addition to the previously determined bischofite and LDH by Mazeina et al. [7], further secondary phases could be identified after the treatment with iso-propanol and a grain size fractionation. Lesukite as main component, Fe-LDH (green rust), lawrencite, elemental iron, and traces of uncorroded fuel $\left(\mathrm{UAl}_{4}\right)$ could be identified unambiguously. Lesukite was not detected by Mazeina et al. [7], on the one hand because of the high amount of bischofite, which was identified as main component in their untreated sample and covered the lesukite. On the other hand, their samples were dialyzed in water, which led to dissolution of the lesukite. The dissolution of lesukite and the formation of Al-hydroxides could be demonstrated in this present study. Furthermore, FeOOH (akaganeite, goethite, and lepidocrocite) could be identified. The appearance of the different oxidation states of iron $(0$, II, III) may be explained by the oxidation of Fe-LDH (green rust) and lawrencite and the formation of Fe-hydroxides, due to an insufficient Ar purge and/or the intrusion of air during the sample treatment. Hence, the Fe-hydroxides may be a corrosion product of the green rust. Furthermore, the results represent a snapshot of the corrosion process and probably implicates that the system is not fully equilibrated. 
Table 3: Qualitative XRD results of the iso-propanol and water treated samples.

\begin{tabular}{|c|c|c|c|c|}
\hline & Fraction & Phase & Formula & Remarks \\
\hline \multirow[t]{16}{*}{ Iso-propanol } & $>63 \mu \mathrm{m}$ & Lesukite & $\mathrm{Al}_{2}(\mathrm{OH})_{5} \mathrm{Cl} \cdot 2 \mathrm{H}_{2} \mathrm{O}$ & \\
\hline & & Mg-LDH & $\mathrm{Mg}_{6} \mathrm{Al}_{2}(\mathrm{OH})_{18} \cdot 4 \mathrm{H}_{2} \mathrm{O}$ & \\
\hline & & $\mathrm{UAl}_{x}$-alloy & $\mathrm{UAl}_{4}$ & \\
\hline & & Goethite & $\mathrm{FeO}(\mathrm{OH})$ & traces \\
\hline & & Lepidocrocite & $\mathrm{FeO}(\mathrm{OH})$ & traces \\
\hline & & Lawrencite & $\mathrm{FeCl}_{2}$ & traces \\
\hline & & Iron (elemental) & $\mathrm{Fe}$ & \\
\hline & & Fe-LDH & $\mathrm{Fe}(\mathrm{OH}, \mathrm{Cl})_{2.55}$ & $\begin{array}{l}\text { Green rust I } \\
\text { (LDH-type) }\end{array}$ \\
\hline & $2-63 \mu \mathrm{m}$ & Lesukite & $\mathrm{Al}_{2}(\mathrm{OH})_{5} \mathrm{Cl} \cdot 2 \mathrm{H}_{2} \mathrm{O}$ & Green rust I \\
\hline & & Mg-LDH & $\mathrm{Mg}_{6} \mathrm{Al}_{2}(\mathrm{OH})_{18} \cdot 4 \mathrm{H}_{2} \mathrm{O}$ & (LDH-type) \\
\hline & & Fe-LDH & $\mathrm{Fe}(\mathrm{OH}, \mathrm{Cl})_{2.55}$ & \\
\hline & & Lawrencite & $\mathrm{FeCl}_{2}$ & \\
\hline & & Akaganeite & $\mathrm{FeO}(\mathrm{OH})$ & \\
\hline & $\overline{<2 \mu \mathrm{m}}$ & Lesukite & $\mathrm{Al}_{2}(\mathrm{OH})_{5} \mathrm{Cl} \cdot 2 \mathrm{H}_{2} \mathrm{O}$ & \\
\hline & & Mg-LDH & $\mathrm{Mg}_{6} \mathrm{Al}_{2}(\mathrm{OH})_{18} \cdot 4 \mathrm{H}_{2} \mathrm{O}$ & \\
\hline & & Akaganeite & $\mathrm{FeO}(\mathrm{OH})$ & \\
\hline \multirow[t]{13}{*}{ Water } & $>63 \mu \mathrm{m}$ & Bayerite & $\mathrm{Al}(\mathrm{OH})_{3}$ & traces \\
\hline & & Gibbsite & $\mathrm{Al}(\mathrm{OH})_{3}$ & \\
\hline & & Nordstrandite & $\mathrm{Al}(\mathrm{OH})_{3}$ & \\
\hline & & Mg-LDH & $\mathrm{Mg}_{6} \mathrm{Al}_{2}(\mathrm{OH})_{18} \cdot 4 \mathrm{H}_{2} \mathrm{O}$ & \\
\hline & & $\mathrm{UAl}_{x}$-alloy & $\mathrm{UAl}_{4}$ & \\
\hline & & Iron (elemental) & $\mathrm{Fe}$ & \\
\hline & $2-63 \mu \mathrm{m}$ & Bayerite & $\mathrm{Al}(\mathrm{OH})_{3}$ & \\
\hline & & Gibbsite & $\mathrm{Al}(\mathrm{OH})_{3}$ & \\
\hline & & Nordstrandite & $\mathrm{Al}(\mathrm{OH})_{3}$ & \\
\hline & & Mg-LDH & $\mathrm{Mg}_{6} \mathrm{Al}_{2}(\mathrm{OH})_{18} \cdot 4 \mathrm{H}_{2} \mathrm{O}$ & \\
\hline & $\overline{<2 \mu \mathrm{m}}$ & Bayerite & $\mathrm{Al}(\mathrm{OH})_{3}$ & \\
\hline & & Gibbsite & $\mathrm{Al}(\mathrm{OH})_{3}$ & \\
\hline & & Nordstrandite & $\mathrm{Al}(\mathrm{OH})_{3}$ & \\
\hline
\end{tabular}

\subsection{Quantification of secondary phases}

Due to the results of the qualitative analysis, the quantification of the secondary phases was only performed on the fractions of the iso-propanol treated samples. Detailed information about the Rietveld refinement and the quantification are presented in an other study [19].

The results of quantitative phase analyses for each grain size fraction are summarized in Table 4.

The smallest fraction, i.e. $<2 \mu \mathrm{m}$ is quantitatively dominated by lesukite exhibiting more than $96.3 \mathrm{wt} .0 \%$. The LDH compounds and akaganeite/goethite are present as accessories, i.e. less than $5 \mathrm{wt} . \mathrm{-} \%$. The amorphous content could be looked upon practically as not existent. The calculated amount of the zincite standard is in very good agreement with the value obtained by weighing.

The grain size fraction $2-63 \mu \mathrm{m}$ is still dominated by lesukite with $64.1 \mathrm{wt} .-\%$. Approximately $25 \mathrm{wt} .-\%$ could be ascribed to the $3 \mathrm{R}$ and $2 \mathrm{H} \mathrm{LDH}$ types containing $\mathrm{Cl}^{-}$in the interlayer. An estimate of $2 \mathrm{wt} \%$ is calculated for the sul- phate LDH. The content of greenrust is very low and exhibits only $0.8 \mathrm{wt} .-\%$. In sum, the iron(oxy)hydroxides akaganeite, goethite, and lepidocrocite do not supersede the 5 wt. $-\%$ threshold and thus have to be considered as accessories, as well. The amorphous content is slightly increased to 3.4 wt. $\%$. The calculated amount of the zincite standard is again in very good agreement with the value obtained by weighing.

This is also valid for the fraction $>63 \mu \mathrm{m}$. Yet, the amorphous content, contrary to the fraction $<63 \mu \mathrm{m}$, rose distinctly and exhibits now more than $38 \mathrm{wt} .-\%$. This increase could be explained by the sample preparation as this fraction is obtained just by sieving, whereas the smaller fraction was additionally subjected to the Atterberg procedure for the further grain size separation. Thereby, it could not be ruled out that amorphous parts, which may have been present after sieving in the smaller fraction were dissolved during this application. 
Table 4: Results of the quantification of the three grain size fractions of the iso-propanol treated sample by Rietveld analysis.

\begin{tabular}{|c|c|c|c|c|c|c|}
\hline \multirow{2}{*}{$\begin{array}{l}\text { Grain size } \\
\text { fraction } \\
\text { Phases }\end{array}$} & \multicolumn{2}{|c|}{$<2 \mu \mathrm{m}$} & \multicolumn{2}{|c|}{$2-63 \mu \mathrm{m}$} & \multicolumn{2}{|c|}{$>63 \mu \mathrm{m}$} \\
\hline & $\begin{array}{c}\text { Mass } \\
\text { [wt.-\%] }\end{array}$ & $\begin{array}{c}\text { Error } \\
{[\%]}\end{array}$ & $\begin{array}{c}\text { Mass } \\
\text { [wt.-\%] }\end{array}$ & $\begin{array}{c}\text { Error } \\
{[\%]}\end{array}$ & $\begin{array}{c}\text { Mass } \\
\text { [wt.-\%] }\end{array}$ & $\begin{array}{c}\text { Error } \\
{[\%]}\end{array}$ \\
\hline Lesukite & 96.3 & 0.3 & 64.1 & 1.2 & 23.4 & 2.1 \\
\hline LDH 2H-Typ & & & 10.6 & 1.6 & 11.5 & 1.6 \\
\hline LDH 3R-Typ & & & 14.0 & 0.9 & 14.3 & 1.4 \\
\hline LDH-Sulfate & & & 2.0 & 0.1 & 3.3 & 0.4 \\
\hline Greenrust & 1.2 & 0.1 & 0.8 & 0.1 & 2.1 & 0.3 \\
\hline Akaganeite & 1.6 & 0.1 & 3.8 & 0.3 & 3.4 & 0.6 \\
\hline Goethite & 0.9 & 0.1 & 0.7 & 0.1 & & \\
\hline Lepidocrocit & & & 0.3 & 0.1 & & \\
\hline Lawrencite & & & & & 1.2 & 0.2 \\
\hline Iron & & & & & 1.3 & 0.2 \\
\hline $\mathrm{UAl}_{4}$ & & & 0.2 & 0.1 & 1.1 & 0.1 \\
\hline $\begin{array}{l}\text { Zincite } \\
\text { calculated }\end{array}$ & 13.7 & 0.2 & 8.5 & 0.3 & 5.8 & 0.4 \\
\hline $\begin{array}{l}\text { Zincite } \\
\text { initial } \\
\text { weight }\end{array}$ & 13.7 & & 8.5 & & 5.9 & \\
\hline Amorphous & 0.0 & 1.9 & 3.4 & 3.1 & 38.4 & 4.2 \\
\hline Rwp & 9 & & 8 & & 0 . & \\
\hline
\end{tabular}

Figure 10 relates the quantities, being normalized for each fraction to the entire amount of secondary phases obtained.

From the grey shaded columns in the last row representing the total of all fractions, it could be seen that the lesukit with more than 51 wt.- $\%$ is the most abundant phase. Second and third ranked are the amorphous phases and the various LDH compounds. All other phases constitute of accessories. From that point of view, the physicochemical properties of the amorphous content have to be evaluated in depth. It is expected that this part contains the uranium as $\mathrm{U}(\mathrm{OH})_{4}$. With exception of the residues of nuclear fuel, no further crystalline uranium phases were observed.

\section{Conclusions}

It can be concluded that after the complete corrosion of the $\mathrm{UAl}_{x}$-Al fuel in $\mathrm{MgCl}_{2}$-rich brine only minor amounts of $\mathrm{Al}$ ( $1-2$ wt. $-\% \pm 0.5$ wt. $-\%$ ) and $\mathrm{U}(3 \mathrm{wt} .-\% \pm 0.5 \mathrm{wt}-\%$ ) remain in the liquid phase. Most of the $\mathrm{Al}$ and $\mathrm{U}$ is present in the solid phase. Hence, during the corrosion, $\mathrm{Al}$ and $\mathrm{U}$ are dissolved and re-precipitated. About half of the added Fe(II) that was used to simulate the corrosion of the container, was found in the solid phase and is bound to secondary phases. The results represent a snapshot of the corrosion process and probably implicate that the system is not fully equilibrated.

A chemical characterization and phase identification of the corrosion products of non-irradiated $\mathrm{UAl}_{x}-\mathrm{Al}$ research reactor fuel elements in $\mathrm{MgCl}_{2}$-rich brine has been presented. For the first time, a sample treatment method, which is common in clay mineralogy and soil science was applied to the separation and enrichment of secondary

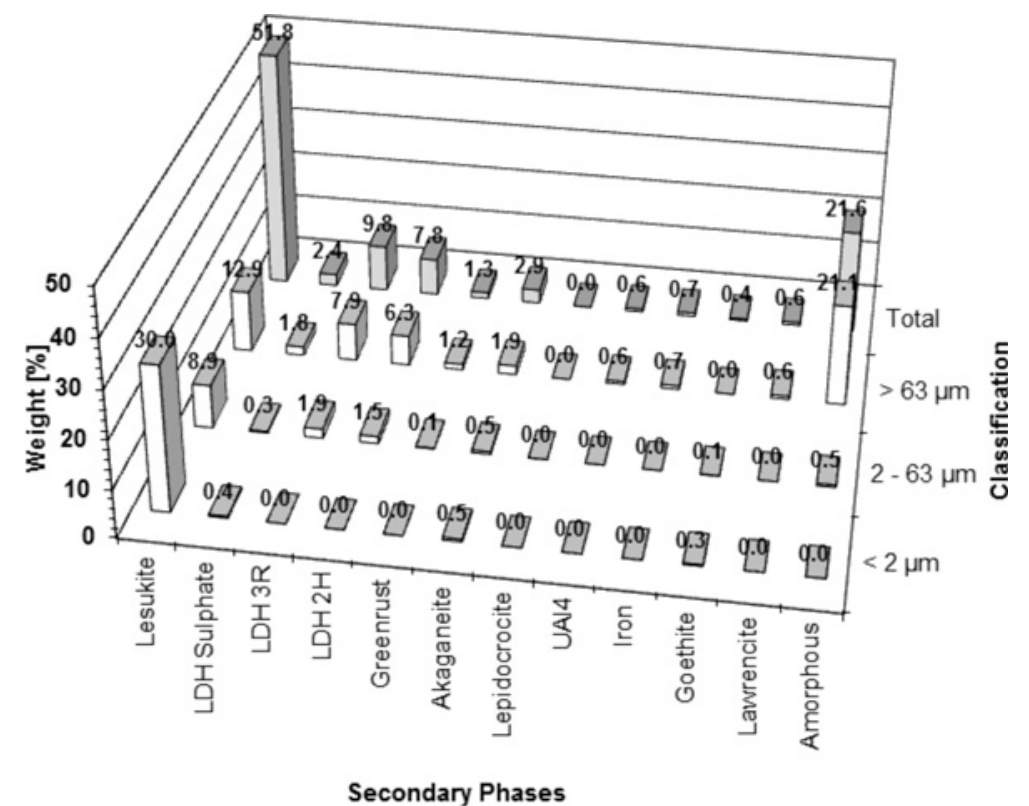

Fig. 10: Quantitative phase distribution in dependence of the grain size fraction. 
phases. A separation and enrichment of secondary phases was achieved by two steps:

1. The treatment with different solvents like acetone, isopropanol, and water.

2. A grain size fractionation.

The fractions $>63 \mu \mathrm{m}, 2-63 \mu \mathrm{m}$ and $<2 \mu \mathrm{m}$ were separated successfully for iso-propanol and water treated samples. In particular, the treatment with iso-propanol is an appropriate procedure to obtain reliable results in terms of the identification of secondary phases. The treatment with water results in dissolution of a main component of the system (lesukite) and does not provide representative results for the secondary phase inventory of the investigated system. A good reproducibility of the sample treatment procedure could be demonstrated. Similar amounts of secondary phases were achieved, similar chemical compositions were determined and the same secondary phases were identified for two identical experiments.

The characterization of the phase of grain size fractionated iso-propanol treated samples by SEM/EDS and XRD reveal that Mg-Al-Cl-LDH, lesukite, Fe-LDH (greenrust), lawrencite, traces of uncorroded fuel $\left(\mathrm{UAl}_{4}\right)$ and elemental $\mathrm{Fe}(0)$ were identified unambiguously. Furthermore, akaganeite, lepidocrocite, and goethite could be identified. In contact with air, green rust and lawrencite transform to goethite, magnetite, and lepidocrocite. Moreover, it could be concluded that these components are formed due to the oxidation of green rust and lawrencite.

The identification of secondary phases could be improved significantly by the treatment with iso-propanol and grain size fractionation.

The iso-propanol treated fractions were used for further XRD-investigations to quantify the crystalline secondary phases by adding an internal standard $(\mathrm{ZnO})$ and subsequent Rietveld analysis. The identification of secondary phases is a key factor with regard to a realistic specification of the near field in a source term, on order to predict the long-term safety of a nuclear waste repository.

\section{References}

1. G. Thamm, Disposal of irradiated fuel elements from German research reactors - Status and Out-look; Trans. Int. Conf. Research Reactor Fuel Management (RRFM 1999), Bruges, Belgium, 159 (1999).

2. M. D. Kaminski, M. M. Goldberg, Aqueous corrosion of aluminium-based nuclear fuel. J. Nucl. Mater. 304 (2002) 182188.
For any considered grain size fraction, the results obtained from this quantification procedure yielded very good and physically reasonable values as an excellent agreement was achieved between the calculated and weighed amounts of zincite. Its admixture gave also allowance to estimate the amorphous content of each grain size fraction being extensively higher for the fraction $>$ $63 \mu \mathrm{m}$. Probably, most of the uranium is associated to these amorphous phases. To clarify the binding mechanisms of $\mathrm{U}$, a characterization and quantification of the amorphous secondary phases will follow in further studies.

Furthermore, corrosion products observed and characterised by the qualitative XRD phase analyses were evidentiary confirmed by SEM and EDX analyses.

The different amounts of amorphous parts and the presence of iron compounds with different valences may be due to the applied grain size separation of the secondary phases, as well. Future work comprising the sample pre-treatment and analysis will thus be done under controlled, improved, and completely anoxic conditions, in order to prevent the secondary phases from alteration.

With respect to the comparative study of $\mathrm{U}_{3} \mathrm{Si}_{2}$-Al fuel in brine 2 [19], it could be clearly stated that this considered system - $\mathrm{UAl}_{x}-\mathrm{Al}$ in brine 2 - behaves in many aspects in a similar manner concerning the qualitative and quantitative phase analyses. In both systems lesukite and LDH compounds are the major phases. Trace amounts of non-corroded fuel were also present and a considerable amount of amorphous phases were observed, as well. Disregarding the observed residues of non-corroded nuclear fuel, a crystalline uranium bearing phase could neither be observed for the $\mathrm{U}_{3} \mathrm{Si}_{2}-\mathrm{Al}$ nor for the $\mathrm{UAl}_{x}-\mathrm{Al}$ system.

Acknowledgement: Financial support by the Bundesministerium für Forschung und Technologie, Germany is acknowledged (BMBF, Förderkennzeichen: 02 E 10357).

Received March 19, 2013; accepted August 22, 2013.
3. M. D. Kaminski, M. M. Goldberg, C. J. Mertz, Colloides from the aqueous corrosion of aluminium-based nuclear fuel. J. Nucl. Mater. 347(2005), 88-93.

4. H. Curtius, G. Kaiser, Z. Paparigas, K. Ufer, E. Müller, R. Enge, H. Brücher, Untersuchungen zum Verhalten von Forschungsreaktor-Brennelementen (FR-BE) in den Wirtsgesteinsformationswässern möglicher Endläger (Investigations of the behaviour of research reactor fuel elements in host rock 
waters of possible repositories). Berichte des Forschungszentrums Jülich, 4237, ISSN 0944-2952, 2006.

5. H. Curtius, G. Kaiser, E. Müller, D. Bosbach, Radionuclide release from research reactor spent fuel, Journal of Nuclear Materials (2011), doi:10.1016/j.jnucmat.2010.12.221.

6. A. Loida, B. Grambow, H. Geckeis, Anoxic corrosion of various high burnup spent fuel samples. J. Nucl. Mater. 238 (1996) 11-22.

7. L. Mazeina, H. Curtius, J. Fachinger, R. Odoj, Characterisation of secondary products of uranium-aluminium material test reactor fuel element corrosion in repository-relevant brine. J. Nucl. Mater. 321 (2003) 1-7.

8. H. Curtius, Z. Paparigas, G. Kaiser, Sorption of selenium on MgAl and Mg-Al-Eu layered double hydroxides. Radiochimica Acta 96 (2008) 651-655.

9. H. Curtius, K. Ufer, Eu incorporation behavior of a Mg-Al-Cl layered double hydroxide. Clays and Clay Minerals 55 (2007) 354-360.

10. W. Hiltmann, B. Stribrny, Tonmineralogie und Bodenphysik. Handbuch zur Erkundung des Untergrundes von Deponien und Altlasten, Band 5. BGR, Bundesanstalt für Geowissenschaften und Rohstoffe. ISBN 3-540-59465-5 Springer-Verlag, 1998.

11. H. Brücher, H. Curtius, J. Fachinger, G. Kaiser, L. Mazeina, K. $\mathrm{Nau}$, Untersuchungen zur Radionuklidfreisetzung und zum Korrosionsverhalten von bestrahltem Kernbrennstoff aus Forschungsreaktoren unter Endlagerbedingungen. Berichte des Forschungszentrums Jülich, 2001.

12. B. Kienzler, A. Loida (Hrsg.), Endlagerrelevante Eigenschaften von hochradioaktiven Abfallprodukten - Charakterisierung und
Bewertung - Empfehlungen des Arbeitskreises HAW-Produkte; Wissenschaftliche Berichte FZKA 6651, Institut für Nukleare Entsorgungstechnik, Forschungszentrum Karlsruhe, 2001.

13. B. Grambow, R. Müller, Chemistry of Glass Corrosion in High Saline Brines. Material Resources Society Symposium Proceedings, Vol 176, 229-240.

14. J. Burgess, Metal Ions in Solution. Ellis Horwood, New York, (1978) ISBN 0-85312-027-7.

15. H. M. Rietveld, Line profiles of neutron powder-diffraction peaks for structure refinement. Acta Crystallographica 22 (1967) 151-152.

16. H. M. Rietveld, A profile refinement method for nuclear and magnetic structures. Journal of Applied Crystallography 2 (1969) 65-71.

17. R. W. Cheary, A. A. Coelho, A fundamental parameters approach to X-ray line-profile fitting. Journal of Applied Crystallography 25(2) (1992) 109-121.

18. J. Bergmann, P. Friedel, R. Kleeberg, BGMN - a new fundamental parameters based Rietveld program for laboratory X-ray sources, its use in quantitative analysis and structure investigations. CPD Newsletter (20) (1998) 5-8.

19. A. Neumann, Bildung von sekundären Phasen bei tiefengeologischer Endlagerung von Forschungsreaktor-Brennelementen Struktur- und Phasenanalyse (2012). PhD Thesis, RWTH Aachen University. Schriften des Forschungszentrums Jülich, Energy \& Environment, Volume 153, ISBN 978-3-89336-822-8. 